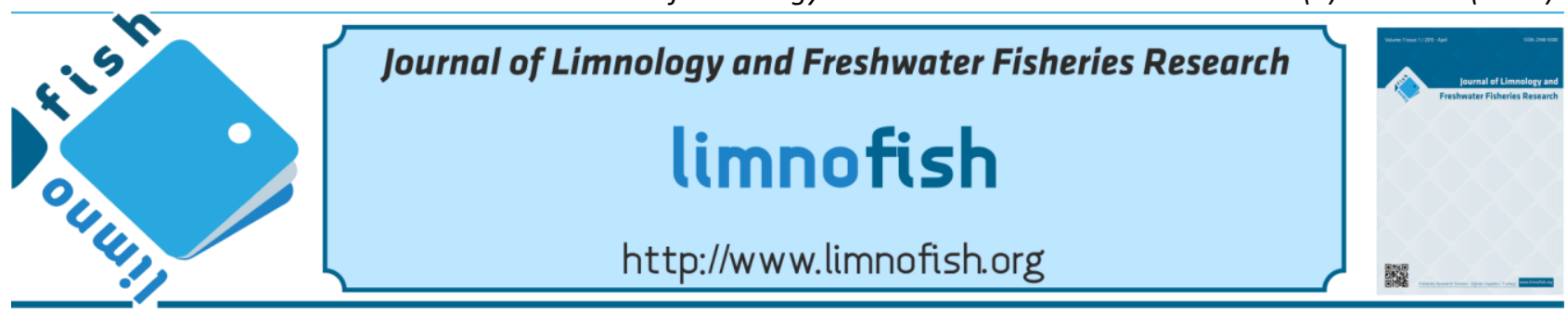

\title{
Uluabat Gölü Epifitik Diyatomelerinin Uzun Dönemdeki Değişimi
}

\author{
Nurhayat DALKIRAN*, Burcu ZÜNBÜLGILL, Didem KARACAOĞLU, Şükran DERE
}

Uludağ Üniversitesi, Fen-Edebiyat Fakültesi, Biyoloji Bölümü, BURSA

\section{$\ddot{O} z$}

Bu çalışmada, Uluabat Gölü kıyı bölgesinde iki farklı periyotta (Temmuz 1998 Haziran 1999 ve Haziran 2014 - Mayıs 2015) tespit edilen epifitik diyatome tür çeşitliliğinin karşılaştırılması amaçlanmıştır. Temmuz 1998-Haziran 1999 çalışma döneminde Bacillariophyta divizyosuna ait 214 takson tespit edilirken, Haziran 2014 - Mayıs 2015 çalışma döneminde takson sayısı 86 olarak belirlenmiştir. Her iki çalışma döneminde de nispi bolluk ve tekerrür oranları açısından baskın olan en önemli taksonlar Cocconeis placentula var. lineata (Ehrenberg) van Heurck, Nitzschia amphibia Grunow ve Rhoicosphaenia abbreviata (C.Agardh) Lange-Bertalot olmuștur. Yapılan bu iki çalışma karşılaştırıldığında epifitik diyatome florası takson sayısının yıllara göre azaldığı tespit edilmiştir. Epifitik diyatome takson zenginliğinin azalmasının sebebinin yıllara bağlı olarak gölde artan kirlilik yükü ve ötrofikasyon seviyesi artışı olduğu düşünülmektedir.

Anahtar kelimeler: Uluabat Gölü, epifitik diyatomeler, takson zenginliği

\section{MAKALE BILGISI}

ARAŞTIRMA MAKALESI
$\begin{array}{ll}\text { Geliş } & : 15.07 .2016 \\ \text { Düzeltme } & : 05.10 .2016 \\ \text { Kabul } & : 11.10 .2016 \\ \text { Yayım } & : 23.12 .2016\end{array}$

DOI: $10.17216 /$ LimnoFish.279724

\section{* SORUMLU YAZAR}

dalkiran@uludag.edu.tr

Tel : +902242941866

Faks : +902242941898

\section{The Alternation of Epiphytic Diatoms at Lake Uluabat in the Long Period}

\begin{abstract}
In this study, we aimed to compare epiphytic diatom species diversity, which identified at two different periods (July 1998 - June 1999 and June 2014 - May 2015) at littoral zon of Lake Uluabat. 214 taxa were identified belonging to Bacillariophyta division during the study period of July 1998 to June 1999, while 86 taxa at June 2014 - May 2015. Cocconeis placentula var. lineata (Ehrenberg) van Heurck, Nitzschia amphibia Grunow and Rhoicosphaenia abbreviata (C.Agardh) Lange-Bertalot were the most important taxa in terms of dominancy of relative abundance and repetition rates at both two study periods. When comparing these two studies, taxa richness of epiphytic diatom flora has been found to be reduced by years. Increasing pollution load and eutrophication level at the lake due to years, thought to be the cause of the decline of epiphytic diatom taxa richness.
\end{abstract}

Keywords: Lake Uluabat, epiphytic diatoms, taxa richness

\section{Alıntılama}

Dalkıran N, Zünbülgil B, Karacaoğlu D, Dere Ş. 2016. Uluabat Gölü epifitik diyatomelerinin uzun dönemdeki değişimi. LimnoFish. 2(3):153-163. doi: 10.17216/LimnoFish.279724

\section{Giriş}

Sucul ekosistemlerde alglerin dağılımı, suyun fiziksel ve kimyasal yapısına ve içeriğine bağlı olarak büyük değişiklikler göstermektedir. Özellikle insanların önemli besin kaynaklarından biri olan balık ve göllerde yaşayan diğer canlıların birincil ürününü oluşturan algler, ortam şartlarından etkilenerek ya aşırı derecede çoğalmakta ya da yok olmaktadır. Dolayısıyla belirli periyotlarla sucul ekosistemlerin alg tür ve populasyonlarının belirlenmesi, bir gölün trofik seviyesinin ve verimliliğinin belirlenmesi bakımından da önem taşımaktadır.

Tüm sucul ekosistemler gibi göller de kirlilik, su kaynaklarının bozulması ve ötrofikasyon gibi olumsuz etkilere maruz kalırlar. Diyatomeler biyoindikatör olmaları ve ekolojik açıdan önem taşımaları nedeni ile sucul habitatlardaki çevresel tahribatları belirlemede uygun biyolojik bileşenlerdendir. Aynı zamanda su kalitesinin belirlenmesinde biyoindikatör olarak da kullanılırlar. Suyun fiziksel ve kimyasal yapısındaki değişimlere karşı da oldukça hassastırlar.

Uluabat Gölü ötrofik karakterli sığ bir göldür. Su seviyesi mevsimlere bağlı olarak değişiklik göstermektedir (Dalkıran vd. 2006). Aynı zamanda çok zengin bir flora ve faunaya sahiptir (Karacaoğlu vd. 2004; Çınar vd. 2013). Zengin tür çeşitliliğine sahip bir sulakalan olmasından dolayı, 1998 yılında RAMSAR alanı ilan edilmiştir. Ülkemizdeki 14 
RAMSAR alanından biri olan göl aynı zamanda "Uluslararası Yaşayan Göller Ağı"na dahil ülkemizdeki iki gölden biridir. Ancak gölde y1llara bağlı olarak artış gösteren kirlilik ve ötrofikasyon göldeki biyolojik çeşitliliği tehdit eden en önemli faktörlerdir. $\mathrm{Bu}$ çalışmada Uluabat Gölü sulak alanının epifitik diyatome tür çeşitliliğinin uzun dönemdeki değişiminin belirlenmesi amaçlanmıştır.

\section{Materyal ve Metot}

\section{Çalışma Alanının Tanımı}

Uluabat Gölü, Bursa sınırları içinde, Marmara Denizi'nin güneyinde, doğu-batı doğrultusunda uzanmaktadır. Göl, Manyas Gölü ile birlikte tektonik hareketlerle oluşmuştur (Kazanc1 vd. 2004). Gölü besleyen Mustafakemalpaşa Çayı ve bu çayın iki kolu Orhaneli ve Emet çayları nedeni ile göl havzası Güneyde Kütahya-Gediz eteklerine kadar uzanan Susurluk Havzası içinde kalan çok önemli bir su kaynağıdır. Gölü besleyen Mustafakemalpaşa Çayı ve iki kolu Emet ve Orhaneli çaylarında oluşan kirlilik doğrudan göle yansımaktadır (Dalkıran 2000).

Uluabat Gölü'nün doğu-bat1 istikametinde uzunluğu 23-24 km, genişliği ise $12 \mathrm{~km}$ kadardır. Ancak gölün alanı yıllara ve mevsimlere göre değişiklik göstermektedir. Landsat uydu görüntülerine göre 14 y1llık bir süre içinde göl yüzey alanının ve hacminin \% 12 azalmış olduğu belirlenmiştir (Karaer vd. 2011). Göl derinliği özellikle yaz aylarında 1,5 m'ye kadar düşmektedir (Kazanc1 vd. 2004; Dalkıran vd. 2006; Karaer vd. 2011).

Orhaneli Çayı üzerinde inşa edilen Çınarcık Barajı 2006 yılında, Uluabat Gölü Kuvvet Tüneli ve HES Projesi ise 2008 yılında tamamlanmıştır. Kuvvet tünelinden çıkan suyun HES'te enerjisi alındıktan sonra Fadıllı Köyü yakınlarından göle bırakılmaktadır. Suyun bu istikametten göle bırakılmasının göl suyunun hidrodinamik yapısını ve su kalitesini önemli ölçüde değiştireceği düşünülmektedir.

Uluabat Gölü zengin biyolojik çeşitliği ile ülkemizin en önemli sulak alanlarından biridir. Gölün hemen hemen bütün kıyıları geniş sazlıklarla kaplıdır (Anonim 1997; Seçmen ve Leblebici 1997). Phragmites australis (Cav.) Trin. ex. Steud (kamış), Sparganium erectum L. ssp. erectum (dik sığır sazı), Bolboschoenus maritimus Palla var. maritimus (deniz sandalye sazı), Typha domingensis Pers. (dar yapraklı saz) buna örnek verilebilir (Anonim 1997; Seçmen ve Leblebici 1997). Gölde yaygın olarak bulunan suya batık sucul bitkilere ise Ceratophyllum demersum L. (tilkikuyruğu), Potamogeton crispus L. (kıvırcık su sümbülü), Vallisneria spiralis L. (yılanbalığı otu), Myriophyllum spicatum L. (başaklı su civanperçemi) örnek olarak verilebilir (Anonim 1997; Seçmen ve Leblebici 1997). Gölün kuzey batısında Türkiye'nin en geniş Beyaz Nilüfer (Nymphaea alba L.) yatakları mevcuttur.

Uluabat Gölü balıkların üreme ve beslenmeleri açısından da önemli bir alandır. Gölde 21 balık türü kaydedilmiştir (Berber vd. 2011; Çınar vd. 2013). Bu göl, aynı zamanda kuş varlığ 1 yönünden sadece ülkemizin değil, Avrupa ve Ortadoğu'nun da en önemli sulak alanlarından birisidir. 1996 yılı Ocak ayında gölde 429423 adet su kuşu sayılmış olup, bu say1 1970 yılından bu yana Türkiye'de bir sulak alanda kaydedilmiş en yüksek sayıdır (Welch ve Welch 1998).

\section{Örnek AIma İstasyonları}

Epifitik diyatome örnekleri, Temmuz 1998Haziran 1999 tarihleri arasında aylık olarak beş ayrı istasyondan alınmıştır. 1. istasyon olarak gölün boşalımının gerçekleştiği, Uluabat köyünde bulunan gölayağı seçilmiştir. 2. istasyon Halilbey adasının kuzeyindedir. 3. istasyon Eskikaraağaç köyü kıyı bölgesindedir. 4. istasyon, Gölyazı (Apolyont) köyünün kıyı bölgesinden belirlenmiştir. 5. istasyon olarak ise Akçalar kasabası kıyısında, Musa deresinin göle boşaldığı yerin hemen yanı seçilmiştir. Temmuz 1998 - Haziran 1999 tarihleri arasında örneklenen 5 istasyondan 59 örnekleme yapılmış, Aralık ayında Akçalar noktasından örnekleme yapılamamıştır.

Epifitik diyatome örnekleri, Haziran 2014- Mayıs 2015 tarihleri arasında da aylık olarak beş ayrı istasyondan alınmıştır. Ancak gölde belirlenen istasyonlar 1998 - 1999 yılları arasındaki çalışmadan biraz farklılık göstermektedir. Özellikle Çınarcık Barajı'nın yapılmasıyla birlikte göle etkisini de araştırmak amacı ile barajdan gelen suyu göle bırakan kuvvet tünelinin yanı bir istasyon olarak belirlenmiştir. 2014-2015 yılları arasındaki istasyonlar sirasiyla 1. istasyon Uluabat Pompa istasyonu, 2. istasyon Gölkıyı, 3. istasyon Eskikaraağaç Köyü, 4. istasyon Gölyazı, 5. istasyon Kuvvet Tüneli'dir. Haziran 2014-Mayis 2015 tarihleri arasında beş farklı istasyondan 56 örnekleme yapılmış, Aralık 2014 tarihinde Eskikaraağaç, Gölkıyı ve Gölyazı istasyonlarından ve Ocak 2015 tarihinde ise Kuvvet Tüneli istasyonundan örnek alınamamıştır. Farklı yıllardaki örneklemeleri haritada belirtmek için Temmuz 1998 - Haziran 1999 tarihleri arasındaki istasyonlar A, Haziran 2014Mayıs 2015 tarihleri arasındaki istasyonlar ise B ile kodlanmıştır. İstasyonların gösterildiği harita Şekil 1 'de verilmiştir.

\section{Yöntem}

Temmuz 1998 - Haziran 1999 tarihleri arasinda yapılan çalışmada epifitik diyatome örnekleri büyük 
oranda M. spicatum, C. demersum, V. spiralis, Chara sp. taksonlarından örneklenmiş, bu bitkilerin bulunmadığı bazı aylarda ise epifitik diyatomeleri örneklemek için dal ve çeşitli yaprak parçaları kullanılmıştır. Haziran 2014 - Mayıs 2015 tarihleri arasında yapılan çalışmada ise epifitik diyatome örnekleri genellikle $C$. demersum ve $V$. spiralis bitkileri üzerinden toplanmıştır. Özellikle bu bitkilerin bulunmadığı kış periyodunda ise Chara sp., Cladophora sp. veya dal ve çeşitli yaprak parçaları kullanılmıştır. Bitkiler üzerinde yaşayan epifitik diyatomeler laboratuvarda naylon bir firça yardımıyla bitkilerin üzerlerinden temizlenmiş ve saf su ile 50 ml'ye tamamlanmıștır. Elde edilen örneklerin bir kısmı $(10 \mathrm{ml}) \%$ 4'lük formaldehit çözeltisi ile tespit edilerek saklanmıştır. Diğer kısmı ise $(20 \mathrm{ml})$ organik materyalin uzaklaştırılması ve diyatome früstüllerinin tayinleri için kullanılmıştır.
Temmuz 1998 - Haziran 1999 tarihleri arasında yapılan çalışmada diyatome früstüllerini temizlemek için örneklere eşit hacimlerde $\mathrm{H}_{2} \mathrm{SO}_{4}$ ve $\mathrm{HNO}_{3}$ ilave edilerek çeker ocakta kaynatılmıştır. Haziran 2014Mayıs 2015 tarihleri arasında yapılan çalışmada ise 'soğuk asit permanganat yöntemi' (Kelly vd. 2001) diyatome früstüllerindeki organik materyalin uzaklaştırılması amacı ile uygulanmıştır. Diyatome örneklerinin sayımı ve tayinleri için örnekler lam üzerine damlatılarak kurutulmuş ve entellan kullanılarak daimi preparat haline getirilmiştir. Epifitik diyatomelerin taksonomik tayinleri Hustedt (1930), Patrick ve Reimer (1966, 1975), Round vd. (1990) ve Krammer ve Lange-Bertalot'a (1991a, 1991b, 1997a, 1997b) göre gerçekleştirilmiştir. Taksonların güncel isimleri algaebase.org internet sitesinden kontrol edilmiştir (Guiry ve Guiry 2016).

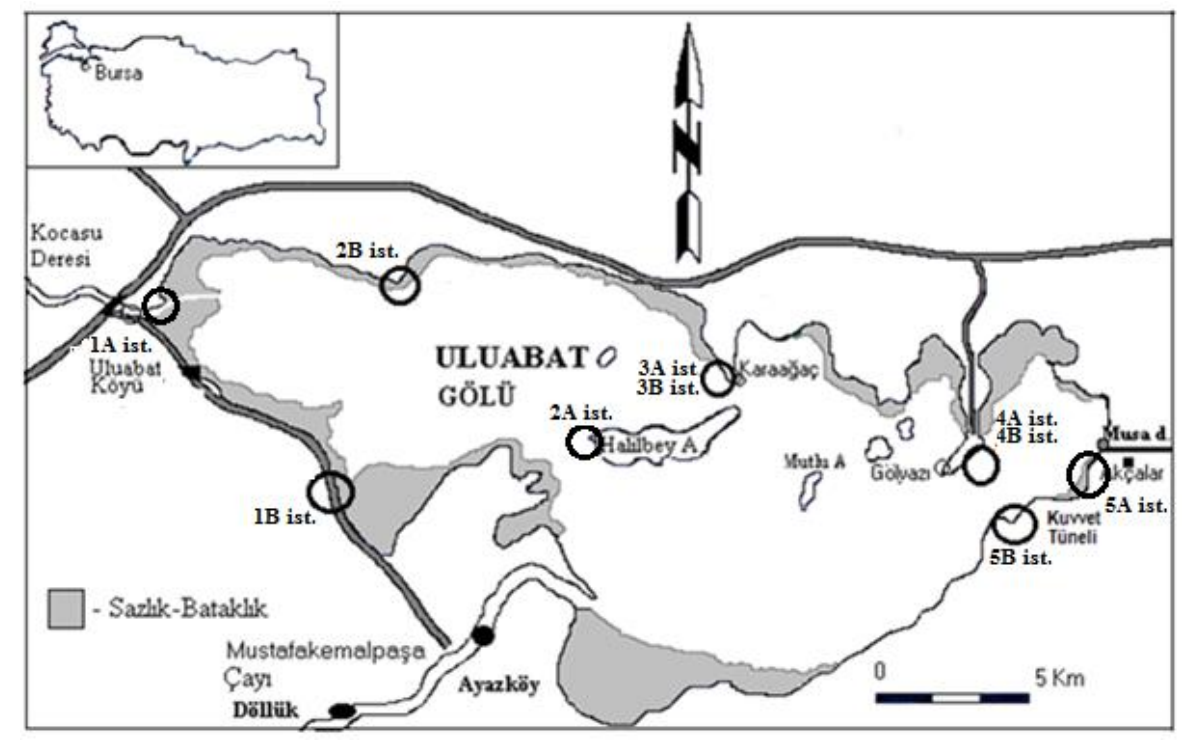

Şekil 1. Uluabat Gölü örnekleme istasyonları

\section{Bulgular}

Temmuz 1998 - Haziran 1999 tarihleri arasinda aylık olarak beş ayrı istasyonda yapılan çalışmada Uluabat Gölü epifitik diyatome florasında Bacillariophyta divizyosuna ait toplam 214 takson tespit edilmiştir (Çizelge 1). Haziran 2014 - Mayıs 2015 tarihleri arasında yapılan çalışmada ise Bacillariophyta divizyosuna ait toplam 86 takson tespit edilmiştir (Çizelge 1). Her iki çalışma döneminde tespit edilen toplam takson sayısı ise 226'dır. Taksonların çalışma periyoduna ait tekerrür oranları takson listesinin yanında verilmiştir (Çizelge 1).

1998-1999 çalışma döneminde Bacillariophytina subfilumu, Bacillariophycidae alt sinıfina ait 176 takson tespit edilirken 2014 - 2015 çalışma döneminde ise 64 takson tespit edilmiştir. Her iki çalışma periyodunda da Achnanthidium minutissimum, Amphora pediculus, Cocconeis placentula var. lineata, C. pediculus, Gomphonema parvulum, Nitzschia amphibia, $N$. dissipata ve Rhoicosphenia abbreviata tekerrür oranı açısından önemli taksonlar olmuştur. Cocconeis türleri her iki çalışma döneminde de epifitik diyatomelerin en önemli cinsini oluşturmuştur. Cocconeis placentula var. lineata 1998 - 1999 yılları arasındaki çalışmada 59 örneklemenin 57'sinde gözlenirken, 2014 - 2015 yılında yapılan çalışmada 56 örneklemenin 44'ünde tespit edilmiştir. C. pediculus ise her iki örnekleme döneminde sirasıyla 48 ve 47 tekerrür oranlarıyla temsil edilmiştir. Ancak 1998 - 1999 yılları arasındaki çalışmada yüksek tekerrür oranlarına sahip ancak düşük yoğunlukta gözlenen $C$. placentula ve C. placentula var. euglypta 2014 - 2015 çalışma periyodunda tespit edilememiştir. 
Çizelge 1 Uluabat Gölü'nde tespit edilen taksonların listesi.

Periyotlar: 1122

Toplam Tekerrür Oranı: $59 \quad 56$

\section{Empire: Eukaryota \\ Kingdom: Chromista \\ Filum: Bacillariophyta \\ Subfilum: Bacillariophytina \\ Sinıf: Bacillariophyceae \\ Altsinif: Bacillariophycidae}

Toplam Tekeriur Oran: 59 56

Achnanthes coarctata (Brébisson ex W.Smith) Grunow in Cleve \& Grunow

Achnanthidium exiguum (Grunow) Czarnecki

Achnanthidium exiguum var. heterovalvum (Krasske) Czarnecki

Achnanthidium lineare W.Smith

Achnanthidium minutissimum (Kützing) Czarnecki

Adlafia minuscula (Grunow) Lange-Bertalot in Lange-Bertalot \& Genkal

Amphipleura pellucida (Kützing) Kützing

Amphora ovalis (Kützing) Kützing

Amphora pediculus (Kützing) Grunow ex A.Schmidt ${ }^{1}$

Anomoeoneis sphaerophora Pfitzer

Bacillaria paxillifera (O.F.Müller) T.Marsson

Caloneis amphisbaena (Bory) Cleve

Caloneis bacillum (Grunow) Cleve

Caloneis permagna (Bailey) Cleve

Caloneis silicula (Ehrenberg) Cleve

Caloneis ventricosa (Ehrenberg) F.Meister

Caloneis ventricosa var. truncatula (Grunow) Meister

Cocconeis neodiminuta Krammer

$2-$

** -

$4-$

** -

$40 \quad 33$

** -

- 3

$57 \quad-$

$58 \quad 30$

12 -

$11-$

** -

$11-$

** -

- 1

$30-$

$7 \quad-$

** -

$\begin{array}{ll}48 & 47\end{array}$

Cocconeis pediculus Ehrenberg

Cocconeis placentula var. lineata (Ehrenberg) van Heurck

$57 \quad 44$

Cocconeis placentula Ehrenberg

Cocconeis placentula var. euglypta (Ehrenberg) Grunow

Cocconeis scutellum Ehrenberg

Craticula ambigua (Ehrenberg) D.G.Mann

Craticula cuspidata (Kutzing) D.G.Mann in Round, R.M.Crawford \& D.G.Mann

Craticula halophila (Grunow) D.G.Mann in Round, R.M.Crawford \& D.G.Mann

Cymatopleura elliptica (Brébisson) W.Smith

Cymatopleura solea (Brébisson) W.Smith

Cymatopleura solea var. regula (Ehrenberg) Grunow

Cymatopleura solea var. gracilis Grunow

Cymbella affinis Kützing

Cymbella aspera (Ehrenberg) Cleve

Cymbella cistula (Ehrenberg) O.Kirchner

Cymbella cymbiformis C.Agardh

Cymbella helvetica Kützing

Cymbella heterogibbosa H.Kobayasi \& Mayama in Mayama et al.

Cymbella lanceolata (C.Agardh) Kirchner

Cymbella neoleptoceros Krammer

Cymbella parva (W.Smith) Kirchner

Cymbella sp.

Cymbella tumida (Brébisson) van Heurck

Cymbella turgidula Grunow in A.Schmidt et al.

Cymbellafalsa diluviana (Krasske) Lange-Bertalot \& Metzeltin in D.Metzeltin, H.Lange-Bertalot

\& S.Nergui

Cymbopleura naviculiformis (Auerswald ex Heiberg) Krammer

Denticula tenuis Kützing
54 -

50 -

** -

92

13 -

4 -

$11 \quad 1$

432

** -

18 -

5120

- 1

$43 \quad 5$

265

- 36

12 -

531

21 -

4 -

18 -

261

** -

$* * \quad-$ 
Çizelge 1. Devamı

\begin{tabular}{|c|c|c|}
\hline Periyotlar: & 1 & 2 \\
\hline Toplam Tekerrür Oranı: & 59 & 56 \\
\hline Diploneis elliptica (Kützing) Cleve & 10 & - \\
\hline Diploneis oblongella (Nägeli ex Kützing) Cleve-Euler & ** & - \\
\hline Encyonema auerswaldii Rabenhorst & 47 & 1 \\
\hline Encyonema leibleinii (C.Agardh) W.J.Silva, R.Jahn, T.A.Veiga Ludwig \& M.Menezes & 4 & - \\
\hline Encyonema minutum (Hilse) D.G.Mann in Round, R.M.Crawford \& D.G.Mann & $* *$ & - \\
\hline Encyonema silesiacum (Bleisch) D.G.Mann in Round, R.M.Crawford \& D.G.Mann & 15 & - \\
\hline Encyonopsis microcephala (Grunow) Krammer & 1 & 1 \\
\hline Epithemia adnata (Kützing) Brébisson & 52 & 16 \\
\hline Epithemia adnata var. minor (Peragallo \& Héribaud-Joseph) R.M.Patrick in Patrick \& Reimer & 16 & - \\
\hline Epithemia sorex Kützing & 48 & 20 \\
\hline Epithemia sorex var. gracilis Hustedt & 9 & - \\
\hline Epithemia turgida (Ehrenberg) Kützing & 21 & - \\
\hline Fallacia pygmaea (Kützing) Stickle \& D.G.Mann in Round, R.M.Crawford \& D.G.Mann & 12 & - \\
\hline Frustulia rhomboides (Ehrenberg) De Toni & - & 1 \\
\hline Gomphonema acuminatum var. clavus (Brébisson) Grunow in van Heurck & $* *$ & - \\
\hline Gomphonema acuminatum Ehrenberg & 36 & - \\
\hline Gomphonema affine Kützing & 31 & - \\
\hline Gomphonema angustatum var. intermedium Grunow in Van Heurck & $* *$ & - \\
\hline Gomphonema angustatum (Kützing) Rabenhorst & 8 & - \\
\hline Gomphonema augur Ehrenberg & 16 & 11 \\
\hline Gomphonema brebissonii Kützing & 4 & - \\
\hline Gomphonema clavatum Ehrenberg & - & 10 \\
\hline Gomphonema germainii Kociolek \& Stoermer & 25 & \\
\hline Gomphonema gracile Ehrenberg & - & \\
\hline Gomphonema insigne W.Gregory & - & 1 \\
\hline Gomphonema intricatum Kützing & 6 & \\
\hline Gomphonema olivaceum (Hornemann) Brébisson & 51 & 10 \\
\hline Gomphonema olivaceum var. calcareum (Cleve) Van Heurck & 45 & 21 \\
\hline Gomphonema olivaceum var. minutissimum Hustedt & 15 & \\
\hline Gomphonema parvulum (Kützing) Kützing & 51 & 55 \\
\hline Gomphonema sp. & 8 & \\
\hline Gomphonema subtile var. sagitta (Schumann) Grunow in Van Heurck & $* *$ & \\
\hline Gomphonema truncatum Ehrenberg ${ }^{2}$ & 53 & 39 \\
\hline Gomphonema vibrio Ehrenberg & 6 & \\
\hline Gyrosigma acuminatum (Kützing) Rabenhorst & 25 & 1 \\
\hline Gyrosigma scalproides (Rabenhorst) Cleve & ** & - \\
\hline Gyrosigma wormleyi (Sullivant) Boyer & ** & - \\
\hline Halamphora coffeiformis (C.Agardh) Levkov & 38 & \\
\hline Halamphora submontana (Hustedt) Levkov & 7 & - \\
\hline Halamphora veneta (Kützing) Levkov & 15 & 40 \\
\hline Hannaea arcus (Ehrenberg) R.M.Patrick in R.M.Patrick \& L.R.Freese & $* *$ & - \\
\hline Hantzschia amphioxys (Ehrenberg) Grunow & 23 & 8 \\
\hline Hantzschia amphioxys var. major Grunow in Van Heurck & $* *$ & \\
\hline Hippodonta capitata (Ehrenberg) Lange-Bertalot, Metzeltin \& Witkowski & 5 & 5 \\
\hline Hippodonta hungarica (Grunow) Lange-Bertalot, Metzeltin \& Witkowski & 20 & \\
\hline Hippodonta luneburgensis (Grunow) Lange-Bertalot, Metzeltin \& A.Witkowski & 3 & \\
\hline Lemnicola hungarica (Grunow) Round \& Basson & 9 & \\
\hline Luticola cohnii (Hilse) D.G.Mann in Round, R.M.Crawford \& D.G.Mann & 8 & \\
\hline Luticola mutica (Kützing) D.G.Mann in Round, R.M.Crawford \& D.G.Mann & 5 & - \\
\hline Luticola undulata (Hilse) D.G.Mann in Round, R.M.Crawford \& D.G.Mann & $* *$ & - \\
\hline Navicula capitatoradiata Germain & 55 & 28 \\
\hline Navicula cincta (Ehrenberg) Ralfs in Pritchard & 19 & \\
\hline Navicula contempta Krasske & 9 & \\
\hline
\end{tabular}


Çizelge 1. Devamı

\begin{tabular}{|c|c|c|c|}
\hline & Periyotlar: & 1 & 2 \\
\hline & Toplam Tekerrür Oranı: & 59 & 56 \\
\hline Navicula cryptocephala Kützing & & 54 & - \\
\hline Navicula cryptotenella Lange-Bertalot & & 47 & 31 \\
\hline Navicula erifuga Lange-Bertalot in Krammer \& Lange-Bertalot & & 5 & - \\
\hline Navicula exigua Gregory & & 1 & 1 \\
\hline Navicula exigua var. capitata R.M.Patrick & & $* *$ & - \\
\hline Navicula gothlandica Grunow & & 1 & 1 \\
\hline Navicula gregaria Donkin & & 9 & - \\
\hline Navicula heufleri Grunow & & 11 & - \\
\hline Navicula lanceolata Ehrenberg & & $* *$ & - \\
\hline Navicula menisculus Schumann & & 26 & - \\
\hline Navicula oblonga (Kützing) Kützing & & 16 & - \\
\hline Navicula radiosa Kützing & & 37 & 13 \\
\hline Navicula reinhardtii (Grunow) Grunow in Van Heurck & & $* *$ & - \\
\hline Navicula rhynchocephala Kützing & & 26 & - \\
\hline Navicula sp. & & 12 & - \\
\hline Navicula tripunctata (O.F.Müller) Bory de Saint-Vincent & & 57 & 39 \\
\hline Navicula tripunctata var. schizonemoides (Van Heurck) R.M.Patrick & & $* *$ & - \\
\hline Navicula veneta Kützing & & 57 & 28 \\
\hline Navicula viridula var. linearis Hustedt & & $* *$ & - \\
\hline Navicula viridula (Kützing) Ehrenberg & & 11 & - \\
\hline Neidium affine (Ehrenberg) Pfitzer & & ** & - \\
\hline Neidium dubium (Ehenberg) Cleve & & ** & - \\
\hline Nitzschia acicularis (Kützing) W.Smith & & 8 & - \\
\hline Nitzschia amphibia Grunow & & 54 & 54 \\
\hline Nitzschia capitellata Hustedt & & - & 1 \\
\hline Nitzschia dissipata (Kützing) Rabenhorst & & 43 & 46 \\
\hline Nitzschia filiformis (W.Smith) Van Heurck & & 6 & - \\
\hline Nitzschia fonticola (Grunow) Grunow & & 9 & 30 \\
\hline Nitzschia frustulum (Kützing) Grunow & & 30 & 1 \\
\hline Nitzschia gracilis Hantzsch & & 28 & - \\
\hline Nitzschia holastica Hustedt & & 39 & - \\
\hline Nitzschia inconspicua Grunow $^{3}$ & & 52 & 19 \\
\hline Nitzschia linearis W.Smith & & 15 & 12 \\
\hline Nitzschia lorenziana var. subtilis Grunow & & 3 & - \\
\hline Nitzschia microcephala Grunow & & 4 & 10 \\
\hline Nitzschia obtusa W.Smith & & $* *$ & - \\
\hline Nitzschia palea (Kützing) W.Smith & & 55 & 28 \\
\hline Nitzschia paleacea Grunow & & 34 & 5 \\
\hline Nitzschia parvula W.Smith & & $* *$ & - \\
\hline Nitzschia recta Hantzsch ex Rabenhorst & & 22 & 22 \\
\hline Nitzschia sigmoidea (Nitzsch) W.Smith & & 28 & - \\
\hline Nitzschia sp. & & $* *$ & - \\
\hline Nitzschia spectabilis (Ehrenberg) Ralfs & & 6 & - \\
\hline Nitzschia sublinearis Hustedt & & 4 & - \\
\hline Nitzschia umbonata (Ehrenberg) Lange-Bertalot & & 20 & - \\
\hline Nitzschia vermicularis (Kützing) Hantzsch in Rabenhorst & & 11 & - \\
\hline Nitzschia vitrea G.Norman & & $* *$ & - \\
\hline Parlibellus protractus (Grunow) Witkowski, Lange-Bertalot \& Metzeltin & & 4 & - \\
\hline Pinnularia angulosa Krammer & & $* *$ & - \\
\hline Pinnularia angusta (Cleve) Krammer & & $* *$ & - \\
\hline Pinnularia brebissonii (Kützing) Rabenhorst & & 12 & - \\
\hline Pinnularia maior (Kützing) Cleve & & 12 & - \\
\hline Pinnularia obscuriformis Krammer & & 2 & \\
\hline
\end{tabular}


Çizelge 1. Devamı

\begin{tabular}{|c|c|c|}
\hline Periyotlar: & 1 & 2 \\
\hline Toplam Tekerrür Oranı: & 59 & 56 \\
\hline Pinnularia viridis (Nitzsch) Ehrenberg & - & 1 \\
\hline Pinnularia viridis var. commutata (Grunow) Cleve & 9 & - \\
\hline Pinnularia viridis var. minor Cleve & 10 & - \\
\hline Placoneis elginensis (W.Gregory) E.J.Cox ${ }^{4}$ & 13 & - \\
\hline Planothidium lanceolatum (Brébisson ex Kützing) Bukhtiyarova & 27 & 9 \\
\hline Planothidium lanceolatum var. omissum (C.W.Reimer) N.A.Andresen, Stoermer \& R.G.Kreis & $* *$ & - \\
\hline Reimeria sinuata (W.Gregory) Kociolek \& Stoermer & ** & - \\
\hline Rhoicosphenia abbreviata (C.Agardh) Lange-Bertalot & 56 & 49 \\
\hline Rhopalodia gibba var. ventricosa (Kützing) H.Peragallo \& M.Peragallo & 39 & 9 \\
\hline Rhopalodia gibba (Ehrenberg) Otto Müller & 12 & - \\
\hline Sellaphora arvensis (Hustedt) C.E.Wetzel \& L.Ector in Wetzel et al. & 22 & - \\
\hline Sellaphora bacillum (Ehrenberg) D.G.Mann & $* *$ & - \\
\hline Sellaphora pupula (Kützing) Mereschkovsky & 18 & 1 \\
\hline Sellaphora pupula var. capitata (Skvortzov \& K.I.Meyer) & 4 & - \\
\hline Stauroneis anceps Ehrenberg & ** & - \\
\hline Stauroneis gracilis Ehrenberg & ** & - \\
\hline Stauroneis phoenicenteron f. gracilis (Dippel) Hustedt & $* *$ & - \\
\hline Stauroneis phoenicenteron (Nitzsch) Ehrenberg & 4 & - \\
\hline Staurophora soodensis (Krasske) L.Bahls & $* *$ & - \\
\hline Surirella angusta Kützing & 22 & 5 \\
\hline Surirella biseriata Brébisson in Brébisson \& Godey & 18 & - \\
\hline Surirella islandica Østrup & $* *$ & - \\
\hline Surirella linearis W.Smith & 10 & \\
\hline Surirella minuta Brébisson ex Kützing ${ }^{5}$ & 15 & 2 \\
\hline Surirella ovalis Brébisson & 4 & 1 \\
\hline Surirella splendida (Ehrenberg) Kützing & 15 & - \\
\hline Tryblionella angustata W.Smith & 24 & 1 \\
\hline Tryblionella apiculata Gregory & 14 & 14 \\
\hline Tryblionella gracilis W.Smith & 13 & - \\
\hline Tryblionella hungarica (Grunow) Frenguelli & 27 & 2 \\
\hline Tryblionella levidensis W.Smith & 15 & - \\
\hline Tryblionella victoriae Grunow & 5 & - \\
\hline \multicolumn{3}{|l|}{ Sinıf: Eunotiophycidae } \\
\hline Eunotia bilunaris (Ehrenberg) Schaarschmidt & 4 & 4 \\
\hline Eunotia incisa W.Smith ex W.Gregory & $* *$ & - \\
\hline \multicolumn{3}{|l|}{ Altsınıf: Fragilariophycidae } \\
\hline Asterionella formosa Hassall & 18 & - \\
\hline Ctenophora pulchella (Ralfs ex Kützing) D.M.Williams & $* *$ & - \\
\hline Ctenophora pulchella var. lanceolata (O'Meara) L.Bukhtiyarova & 9 & - \\
\hline Diatoma mesodon (Ehrenberg) Kützing & $* *$ & - \\
\hline Diatoma moniliformis (Kützing) D.M.Williams & 6 & 8 \\
\hline Diatoma vulgaris Bory de Saint-Vincent & 10 & 6 \\
\hline Diatoma vulgaris var. producta Grunow & ** & - \\
\hline Fragilaria capucina Desmazières & 20 & 16 \\
\hline Fragilaria crotonensis Kitton & $* *$ & 4 \\
\hline Fragilaria fragilarioides (Grunow) Cholnoky & 13 & 1 \\
\hline Fragilaria socia (Wallace) Lange-Bertalot & 6 & - \\
\hline Fragilaria sp. & 11 & - \\
\hline Fragilaria vaucheriae (Kützing) J.B.Petersen ${ }^{6}$ & 55 & 36 \\
\hline Fragilariforma virescens var. mesolepta (Rabenhorst) N.A.Andresen, Stoermer, \& R.G. Kreis & $* *$ & - \\
\hline Meridion circulare (Greville) C.Agardh & 1 & 1 \\
\hline Pseudostaurosira parasitica (W.Smith) Morales & ** & 5 \\
\hline Staurosirella pinnata (Ehrenberg) D.M.Williams \& Round & - & 32 \\
\hline
\end{tabular}


Çizelge 1. Devamı

\begin{tabular}{|c|c|c|}
\hline Periyotlar: & 1 & 2 \\
\hline Toplam Tekerrür Oranı: & 59 & 56 \\
\hline Synedra familiaris Kützing & 12 & - \\
\hline Tabularia fasciculata (C.Agardh) D.M.Williams \& Round & 3 & 9 \\
\hline Ulnaria acus (Kützing) M.Aboal in Aboal, Alvarez Cobelas, Cambra \& Ector & 26 & 8 \\
\hline Ulnaria biceps (Kützing) P.Compère in Jahn et al. & 27 & 7 \\
\hline Ulnaria capitata (Ehrenberg) P.Compère & 18 & 8 \\
\hline Ulnaria delicatissima (W.Smith) Aboal \& P.C.Silva & 18 & - \\
\hline Ulnaria delicatissima var. angustissima (Grunow) Aboal \& P.C.Silva & 19 & - \\
\hline Ulnaria oxyrhynchus (Kützing) Aboal in Aboal, Alvarez Cobelas, Cambra \& Ector & 30 & - \\
\hline Ulnaria ulna (Nitzsch) P.Compère in Jahn et al. & 56 & 48 \\
\hline \multicolumn{3}{|l|}{ Sinıf: Mediophyceae } \\
\hline \multicolumn{3}{|l|}{ Altsınıf: Thalassiosirophycidae } \\
\hline Coscinodiscus sp. & $* *$ & - \\
\hline Cyclostephanos dubius (Hustedt) Round in Theriot et al. & 46 & - \\
\hline Cyclotella chaetoceras Lemmermann & 5 & - \\
\hline Cyclotella glomerata H.Bachmann & 43 & - \\
\hline Cyclotella iris Brun \& Héribaud-Joseph & - & 10 \\
\hline Cyclotella meneghiniana Kützing & 34 & 35 \\
\hline Cyclotella ocellata Pantocsek & 28 & 26 \\
\hline Lindavia comta (Kützing) Nakov, Gullory, Julius, Theriot \& Alverson & 11 & - \\
\hline Stephanodiscus hantzschii Grunow in Cleve \& Grunow & 15 & - \\
\hline Stephanodiscus niagarae Ehrenberg & 37 & 4 \\
\hline \multicolumn{3}{|l|}{ Subfilum: Coscinodiscophytina } \\
\hline \multicolumn{3}{|l|}{ Sinıf: Coscinodiscophyceae } \\
\hline Aulacoseira granulata (Ehrenberg) Simonsen & 30 & 17 \\
\hline Aulacoseira granulata var. angustissima (O.F.Müller) Simonsen & 9 & 7 \\
\hline Aulacoseira subarctica (Otto Müller) E.Y.Haworth & 55 & - \\
\hline Melosira distans var. lirata (Ehrenberg) VanLandingham & 6 & - \\
\hline Melosira varians C.Agardh & 50 & 48 \\
\hline \\
\hline \multicolumn{3}{|l|}{$\begin{array}{l}{ }^{1} \text { Amphora perpusilla (Grunow) Grunow in Van Heurck ve A. ovalis var. pediculus (Kützing) Van Heurck, A. pediculus } \\
\text { olarak birleştirildi (Krammer va Lange-Bertalot 1997a) }\end{array}$} \\
\hline \multirow{2}{*}{\multicolumn{3}{|c|}{$\begin{array}{l}{ }^{2} \text { Gomphonema truncatum var. capitatum (Ehrenberg) Woodhead \& Tweed, G. truncatum Ehrenberg türünün sinonimi } \\
\text { olarak değiştirildi (Krammer va Lange-Bertalot 1997a) } \\
{ }^{4} \text { Navicula anglica Ralfs in Pritchard ve N. elginensis (W.Gregory) Ralfs in Pritchard türleri Placoneis elginensis türüne } \\
\text { sinonim yapıldı (algaebase.org) }\end{array}$}} \\
\hline & & \\
\hline \multicolumn{3}{|l|}{$\begin{array}{l}{ }^{3} \text { Nitzschia frustulum var. perpusilla (Rabenhorst) Van Heurck, } N \text {. inconspicua Grunow türünün sinonimi olarak } \\
\text { değiștirildi (Krammer va Lange-Bertalot 1997a) }\end{array}$} \\
\hline${ }^{5}$ Surirella ovata ve $S$. ovata var. pinnata, S. minuta olarak birleştirildi (Krammer va Lange-Bertalot 1997a) & & \\
\hline${ }^{6}$ Fragilaria capucina var. vaucheriae ve $F$. intermedia, $F$. vaucheriae olarak birleştirildi (algaebase.org) & & \\
\hline
\end{tabular}

1998 - 1999 döneminde Bacillariophytina subfilumu, Fragilariophycidae alt sinıfina ait 25, 2014 - 2015 döneminde ise 14 takson tespit edilmiştir. Her iki çalışma döneminde de bu alt sınıfa ait en önemli taksonlar Ulnaria ulna ve Fragilaria capucina var. vaucheriae olmuştur.

1998 - 1999 çalıșma döneminde Mediophyceae sinifi, Thalassiosirophycidae altsinifina ait 9 takson tespit edilmiş, ancak bu taksonlardan sadece 4 takson 2014 - 2015 çalışma döneminde epifitik diyatome florasında temsil edilmiştir. Her iki çalışma döneminde de epifitik diyatome florasinda Cyclotella meneghiniana ve $C$. ocellata tekerrür oranı açısından benzerlik göstermiştir.

Coscinodiscophytina subfilumu Coscinodiscophyceae sinıfindan Melosira varians, 1998 - 1999 yılları arasındaki çalışmada 59 örneklemenin 50'sinde gözlenirken, 2014 - 2015 yılında yapılan çalışmada da 56 örneklemenin 48 'inde tespit edilmiştir. Yine Aulacoseira granulata her iki çalışmada da gözlenmesine rağmen, 1998 1999 döneminde tekerrür oran1 (55 tekerrür) açısından önemli olan A. subarctica, 2014 - 2015 periyodunda epifitik örneklemede tespit edilmemiștir. 
Temmuz 1998 - Haziran 1999 çalışma döneminde istasyonlara göre takson zenginliği değerleri oldukça yüksek tespit edilmiş, tüm çalışma dönemi boyunca takson sayısı 40'1n altına düşmemiştir. En düşük takson sayısı 40 olarak Haziran 1999'da Halilbey adasında tespit edilirken, en düşük takson sayısı ise Aralık 1998'de 96 olarak Gölyazı'da tespit edilmiştir
(Şekil 2). Ancak Haziran 2014-Mayıs 2015 çalışma döneminde ise Uluabat Gölü'nde istasyonlara göre diyatome takson zenginliği değerleri oldukça düşük tespit edilmiş, takson zenginliği değerleri 3 ile 37 arasında değişmiştir. En düşük değer Ağustos 2014'te Uluabat Pompa istasyonunda, en yüksek değer ise Aralık 2014'te Gölkıyı'da kaydedilmiştir (Şekil 3).

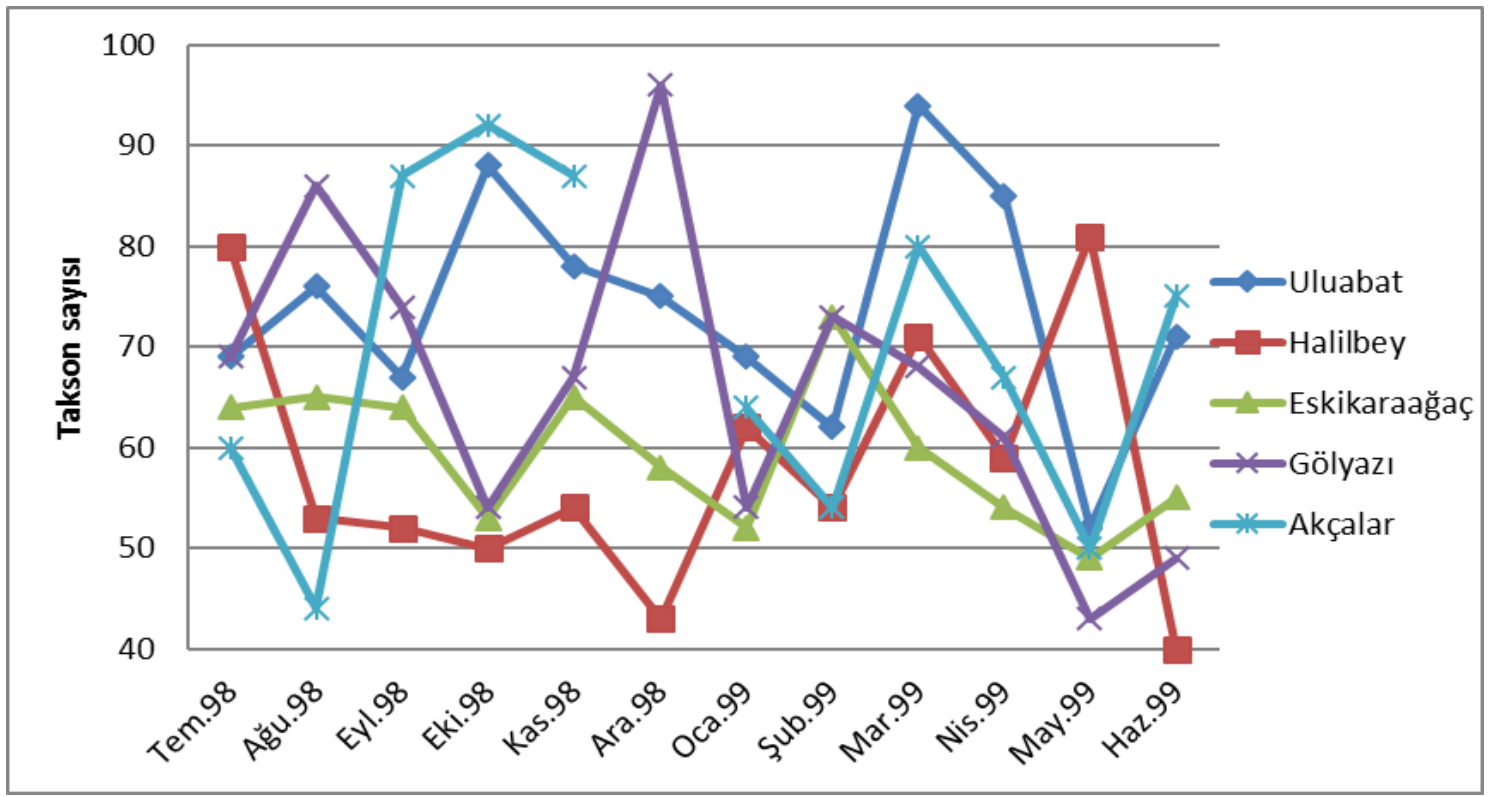

Şekil 2. Temmuz 1998 - Haziran 1999 çalışma döneminde istasyonlara göre takson sayılarının değişimi.

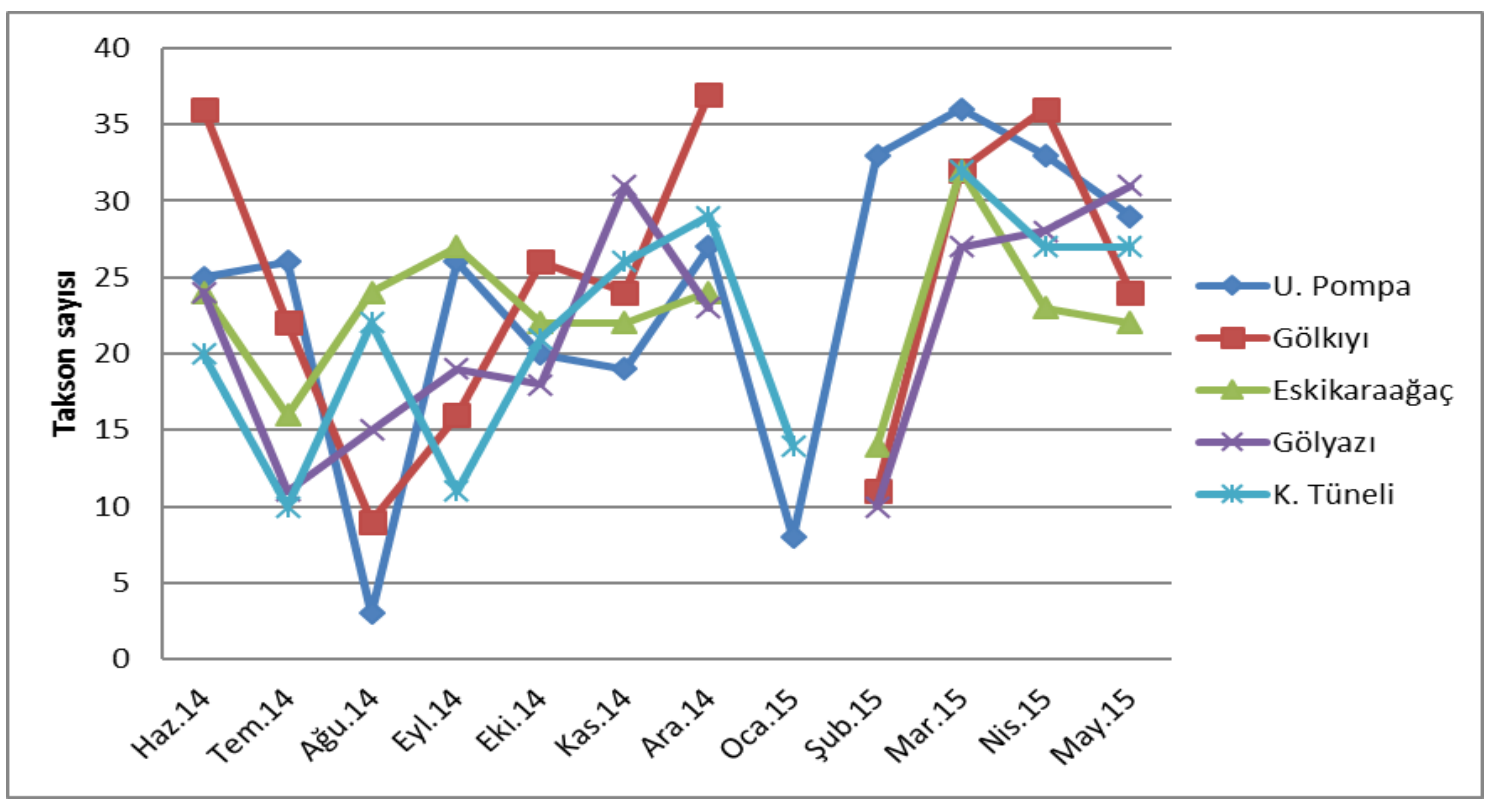

Şekil 3. Haziran 2014- Mayıs 2015 çalışma döneminde istasyonlara göre takson sayılarının değişimi.

\section{Tartışma ve Sonuç}

Uluabat Gölü'nde Temmuz 1998 - Haziran 1999 y1lları arasında yapılan çalışmada epifitik diyatomelere ait toplam 214 takson tespit etmiştir.
Haziran 2014 - Mayıs 2015 tarihleri arasında yapılan çalışmada ise epifitik diyatomeler 86 taksonla temsil edilmiştir. 1998 - 1999 döneminde tespit edilen takson çeşitliliğinin diğer göllerdeki epifitik 
diyatome florası ile karşılaştırıldığında çok yüksek olduğu görülmektedir. Uluabat Gölü epifitik diyatome florasinda tespit edilen taksonların, ülkemizin değişik göllerinde bentik bölgede belirlenen diyatomelerle büyük ölçüde benzerlik gösterdiği belirlenmiştir (Elmacı ve Obalı 1998; Akçaalan 1999; Akköz vd. 2000; Gürbüz 2000; Gürbüz vd. 2002; Çetin vd. 2003; Açıkgöz ve Baykal 2005; Atıc1 vd. 2005; K1vrak ve Gürbüz 2006; Sivac1 vd. 2008; Soylu vd. 2011; Akköz ve Y1lmaz 2009; Barinova vd. 2014; Pala 2014).

İki farklı dönemde yapılan çalışmalar karşılaştırıldığında epifitik diyatome tür çeşitliliğinin azaldığı tespit edilmiştir. Bunun en önemli sebebi yıllara bağlı olarak artan kirlilik yükü ve ötrofikasyon seviyesi olabilir. Yapılan birçok çalışma Uluabat Gölü'nün ötrofik karakterde olduğunu (Elmac1 vd. 2009), hatta hiperötrofiye doğru kaydığını (Karaer vd. 2011; Zünbülgil 2015) göstermektedir. Ayn1 zamanda azot ve fosfor yükünün yıllara bağlı olarak artış gösterdiği de yapılan çalışmalarda gösterilmiştir (Dalkıran vd. 2006, Elmacı vd. 2009, Bulut ve ark. 2010; Karaer vd. 2011; Zünbülgil 2015). Ötrofik su kütlelerinde tür çeşitliliğinin azaldığı ve bazı türlerin daha baskın hale geçtiği bilinen bir durumdur. Velghe vd. (2012), yaptıkları çalışmada artan toplam fosfor miktarına bağlı olarak, littoral diyatome tür çeşitliliğinin anlamlı bir şekilde azaldığını tespit etmişlerdir.

Uluabat Gölü, çalışmanın birinci döneminde fitoplanktonik algler açısından da zengin iken (Karacaoğlu vd. 2004), 2006 yılında yapılan çalışmada takson sayısında yaklaşık yarı yarıya bir düşüş olduğu tespit edilmiştir (Küçükkara vd. 2007). $\mathrm{Bu}$ veri gölde tür azalışı bulgusunu farklı bir habitat açısından desteklemektedir.

İki farklı dönemde yapılan çalışmada ötrofentik karakterli Cocconeis placentula var. lineata, Nitzschia amphibia, Rhoicosphaenia abbreviata (Van dam vd. 1994) taksonlarının tüm istasyonlarda devamlı mevcut olduğu ve yüksek yoğunluk değerlerine sahip olduğu tespit edilmiştir. Haziran 2014 - Mayı 2015 tarihleri arasında yapilan çalışmada, birinci dönemde (Temmuz 1998 - Haziran 1999) yapılan çalışmadan farklı olarak yine ötrofentik karakterli Gomphonema parvulum türü (Van dam vd. 1994) de yüksek yoğunluk değerlerinde gözlenmiştir. McCormick ve Stevenson (1998), G. parvulum ve N. amphibia türlerinin yüksek fosfor mevcudiyetini temsil eden indikatör türler olduğunu söylemektedirler. Ayrıca Fragilaria capucina var. vaucheriae, Melosira varians ve Aulacoseira granulata gibi ötrofentik karakterli (Van dam vd. 1994) taksonların her iki çalışma döneminde de gözlenmesi, 2014 - 2015 yılında yapılan çalışmada A. subarctica gibi oligomesotrafentik karakterli (Van dam vd. 1994) taksonların tespit edilememesi gölde epifitik diyatome florasının yıllara bağlı olarak artış gösteren azot ve fosfor yükünden önemli derecede etkilendiğinin bir diğer göstergesidir.

\section{Teşekkür}

Haziran 2014 - Temmuz 2015 tarihleri arasinda gerçekleştirilen arazi çalışması Orman ve Su İşleri Bakanlığı II. Bölge Müdürlüğü'nün teknik desteği ile gerçekleştirilmiştir.

\section{Kaynaklar}

Açıkgöz İ, Baykal T. 2005. Karagöl (Çubuk-Ankara) alg florası. Eğirdir $\mathrm{Su}$ Ürünleri Fakültesi Dergisi. $1(2): 38-55$.

Akçaalan R. 1999. Manyas Gölü Phragmites australis (su sazı) toplulukları üzerinde yaşayan diyatomelerin mevsimsel değişimleri. [Yüksek Lisans Tezi]. İstanbul Üniversitesi. $47 \mathrm{~s}$.

Akköz C, Küçüködük M, Obalı O, Öztürk C, Doğan H. 2000. Beşgöz Gölü (Sarayönü/Konya) alg florası II: epilitik ve epifitik algler S Ü Fen Fak Fen Derg. 16(1): 5-11.

Akköz C, Yılmaz B. 2009. Suğla Gölü (Seydişehir/Konya) bentik algleri üzerine araştırmalar. S Ü Fen Fak Fen Derg. 33(2): 51-59.

Anonim 1997. Uluabat Gölünde yabanc1 ot sorunları konusunda yapılan çalışmalarla ilgili gezi raporu. DSI I. Bölge Müdürlügüü, Bursa.

Atıcı T, Obalı O, Elmacı A. 2005. Abant Gölü (Bolu) bentik algleri. Ekoloji. 14 (56): 9-15.

Barinova S, Romanov R, Solak CN. 2014. New record of Chara Hispida (L.) Hartm. (Streptophyta: Charophyceae, Charales) from the Iş1klı Lake (Turkey) and critical checklist of Turkish charophytes. Natural Resources and Conservation. 2(3): 33-42. doi: 10.13189/nrc.2014.020301

Berber S, Şaşı H, Topkara ET, Cengiz Ö. 2011. Apolyont Gölü (Bursa) balık faunasının belirlenmesi. İstanbul Üniversitesi Su Ürünleri Dergisi. 26(1): 27-55.

Bulut C, Atay R, Uysal K, Köse E, Çınar Ş. 2010. Uluabat Gölü yüzey suyu kalitesinin değerlendirilmesi. İstanbul Üniversitesi $\mathrm{Su}$ Ürünleri Dergisi. 25 (1): 9-18.

Çetin K, Şen A, Yıldırım B, Alp V. T 2003. Orduzu Baraj Gölü (Malatya, Türkiye) bentik diyatome florası. F Ü Fen ve Mühendislik Bilimleri Dergisi. 15 (1): 1-7.

Çınar Ş, Küçükkara R, Balık İ, Çubuk H. 2013. Uluabat (Apolyont) Gölü'ndeki balık faunasının tespiti, tür kompozisyonu ve ticari avcılığın türlere göre dağılımı. Journal of FisheriesSciencescom. 7(4): 309-316.

Dalkıran N. 2000. Uluabat (Bursa) Gölü'nün epipelik, epifitik ve epilitik alglerinin mevsimsel değişimi. [Yüksek Lisans Tezi]. Uludağ Üniversitesi. 177 s.

Dalkıran N, Karacaoğlu D, Dere Ş, Şentürk E, Torunoğlu T. 2006. Factors affecting the current status of a eutrophic shallow lake (Lake Uluabat, Turkey): Relationships between water physical and chemical variables. Chem Ecol. 22 (4): 279-298. doi: 10.1080/02757540600856229 
Elmacı A, Obalı O. 1998. Akşehir Gölü kıyı bölgesi alg floras1. Turk J Biol. 22(1): 81-98.

Elmacı A, Özengin N, Teksoy A, Olcay Topaç F, Başkaya HS. 2009. Evaluation of trophic state of Lake Uluabat, Turkey. J Environ Biol. 30(5): 757-760.

Guiry MD, Guiry GM. 2016. AlgaeBase. World-wide electronic publication, National University of Ireland, Galway. [Erişim tarihi: $01 \mathrm{Haz}$ 2016]. Erişim Adresi: http://www.algaebase.org

Gürbüz H. 2000. Palandöken Göleti bentik alg florası üzerinde kalitatif ve kantitatif bir araştırma. Turk J Biol. 24(1): 31-48.

Gürbüz H, Kıvrak E, Sülün A. 2002. Porsuk Göleti (Erzurum, Türkiye) bentik alg florası üzerinde kalitatif ve kantitatif bir araştırma. EÜ Su Ürünleri Dergisi. 19(1-2): $41-52$.

Hustedt F, 1930. Bacillariophyta (Diatomeae) Heft: 10 a Pascher Die Susswasser Flora Mitteleuropas, Gustav Fischer, Germany $468 \mathrm{~s}$.

Karacaoğlu D, Dere Ş, Dalkıran N. 2004. A taxonomic study on the phytoplankton of Lake Uluabat (Bursa). Turk J Bot. 28(5):473-485.

Karaer F, Aksoy E, Soyupak S, Muhammetoğlu A, Şentürk E, Aydoğan N. 2011. Uluabat Gölü su kalitesinin modellenmesinde ağır metal ve bazı iz elementlerin değerlendirilmesi. TÜBİTAK Proje No: 107Y278.

Kazancı N, Leroy S, İleri Ö, Emre Ö, Kibar M, Öncel S. 2004. Late halocene erosion in NW Anatolia from sediments of Lake Manyas, Lake Ulubat and the southern shelf of the Marmara Sea, Turkey. Catena. 57(3):277-308. doi:10.1016/j.catena.2003.11.004.

Kelly MG, Adams C, Graves AC, Jamieson J, Krokowski J, Lycett EB, Murray-Bligh J, Pritchard S, Wilkins, C. 2001. The Trophic Diatom Index: A User's Manual Revised edition R\&D Technical Report E2/TR2, Environment Agency, Bristol,135 s.

Kıvrak E, Gürbüz H. 2006. Tortum Gölü’nün (Erzurum) bentik alg florasının mevsimsel değişimi. EÜ Su Ürünleri Dergisi. 23(3-4): 307-313.

Krammer K, Lange-Bertalot H. 1991a. Süßwasserflora von Mitteleuropa Bacillariophyceae 3 Teil: Centrales, Fragilariaceae, Eunotiaceae. Gustav Fischer 576 s.

Krammer K, Lange-Bertalot H. 1991b. Süßwasserflora von Mitteleuropa Bacillariophyceae 4 Teil: Achnanthaceae, Kritische Ergänzungen zu Navicula (Lineolatae) und Gomphonema. Gesamtliteraturverzeichnis. Gustav Fischer 437 s.

Krammer K, Lange-Bertalot H. 1997a. Süßwasserflora von Mitteleuropa Bacillariophyceae 1 Teil: Naviculaceae. Spektrum Akademischer Verlag, Heidelberg Berlin, $875 \mathrm{~s}$.

Krammer K, Lange-Bertalot H. 1997b. Süßwasserflora von Mitteleuropa Bacillariophyceae 2 Teil: Bacillariaceae, Epithemiaceae, Surirellaceae.
Spektrum Akademischer Verlag, Heidelberg Berlin $611 \mathrm{~s}$.

Küçükkara R, Çınar Ş, Uysal R, Çubuk H, Tümgelir L, Erol KG, Çetinkaya S, Atay R, Yeğen V, Savaşer S, Cilbiz M, Meke T, Boyacı YÖ, Akçimen U, Kara D, Korkut SO, Çapkın K, Dalkıran N, Karacaoğlu D, Cilbiz N, Yağcı A, Özkök R, Apaydın Yağcı M, Ceylan M, Bostan H, Cesur M, Bilçen E, Bulut C, Dere Ş. (2007). Uluabat ve İznik göllerindeki ekonomik balı stoklarının tespiti ve sürdürülebilirliklerinin araştırılması. Tarım ve Köy İşleri Bakanlığı Tarımsal Araştırmalar Genel Müdürlüğü TÜGEM-SÜDB sonuç raporu.

McCormick PV, Stevenson RJ. 1998. Periphyton as a tool for ecological assessment and management in the florida everglades. J Phycol. 34 (5): 726-733. doi: 10.1046/j.1529-8817.1998.340726.x.

Pala G. 2014. Hazar Gölü (Suluçayır Düzü) Epifitik Diyatome Florası. Frrat Üniv Fen Bilimleri Dergisi. 26(1): 45-51.

Patrick RC, Reimer W. 1966. The diatoms of the United States. Volume I. The Academy of Natural Sciences of Philadelphia USA $688 \mathrm{~s}$.

Patrick RC, Reimer W. 1975. The diatoms of the United States. Volume II. The Academy of Natural Sciences of Philadelphia USA $213 \mathrm{~s}$.

Round FE, Crawford RM, Mann DG. 1990. The diatoms biology and morphology of the genera. Cambridge University Press, Cambridge, 747 s.

Seçmen Ö, Leblebici E. 1997. Türkiye Sulak Alan Bitkileri ve Bitki Örtüsü. EÜ Fen Fakültesi Kitaplar Serisi No: 158. Bornova İzmir $404 \mathrm{~s}$.

Sıvacı ER, Yardım Ö, Gönülol A, Bat L, Gümüş F. 2008. Sarıkum (Sinop-Türkiye) lagününün bentik algleri. Journal of FisheriesSciencescom. 2(4): 592-600. doi: 10.3153/jfscom.2008022.

Soylu EN, Maraşlığlu F, Gönülol A. 2011. Liman Gölü (Bafra-Samsun) epifitik diatome Florası Ekoloji. 20 (79): 57-62. doi: 10.5053/ekoloji.2011.797.

Van Dam H. Mertens A. Sinkeldam J. 1994. A coded checklist and ecological indicator values of freshwater diatoms from The Netherlands. Neth J Aquat Ecol. 28(1):117-133. doi: 10.1007/BF02334251

Velghe K, Vermaire JC, Gregory-Eaves I. 2012. Declines in littoral species richness across both spatial and temporal nutrient gradients: A palaeolimnological study of two taxonomic groups. Freshwater Biol. 57 (11):2378-2389. doi: 10.1111/fwb.12017

Welch G, Welch H. 1998. Breeding bird survey of Uluabat Lake DHKD $78 \mathrm{~s}$.

Zünbülgil B. 2015. Uluabat Gölü sulakalan bölgesi epifitik diyatomeleri ile su kalitesi arasındaki ilişkiler. [Yüksek Lisans Tezi]. Uludağ Üniversitesi. $161 \mathrm{~s}$. 